\title{
Young people's experience of transition from paediatric to adult haemophilia care in the UK
}

Luke Pembroke, Sandra Dodgson

People with haemophilia and other bleeding disorders, such as von Willebrand's Disease (vWD), are frequently diagnosed in childhood. There is, therefore, a recognised need to prepare children and young people with these conditions for transfer to long-term care in the adult sector.

The Transforming Transition programme was designed to facilitate the sharing of knowledge and experience to enhance transition practice in the UK. The aim of the programme was to secure change in working practices to enable nurses to drive improved transition outcomes, enhance self-management by people with haemophilia and develop clinical leadership.

As part of the programme, we captured young people's views of their transition experiences by means of a series of structured interviews conducted with young people identified through the patient association. Interviews revealed that transition tended to take place around the age of 16 but could be delayed in response to individual circumstances. The transition process did not always appear to be planned, with many participants reporting an abrupt or sudden change between paediatric and adult teams and/or centres.

LUKE PEMBROKE

Haemnet, London. Email: luke@haemnet.com

SANDRA DODGSON

Haemnet, London. Email: sandra@haemnet.com

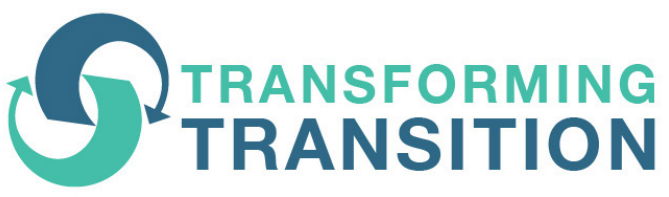

Those with severe haemophilia tended to be well educated and prepared by their paediatric teams to be confident in managing their condition from an early age. They would learn to self-infuse between the ages of 5-11, and reported feeling confident in tailoring their treatment around their daily routine. Experience of transition to adult services varied, with about half describing it as fairly well planned. For those with bleeding disorders such as vWD, there was rarely a transition process. These individuals and people with mild haemophilia described having less exposure to opportunities to learn self-management and appeared to experience issues which coincided with significant lifestyle changes, such as leaving home and attending university. This highlights the importance of ensuring that patients across the spectrum of bleeding disorders are adequately supported in the lead-up to and transfer to adult services. The interviews also reinforce the need to continue to address the specific needs of women with bleeding disorders as they transfer to adult services. The learning from this phase of the Transforming Transition programme was submitted to NICE as part of the consultation on its guideline.

Keywords: Transition, patient views, haemophilia, young people 


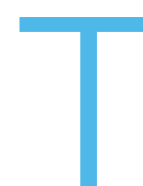
he need to prepare children and young people with haemophilia for long-term care in the adult sector has long been accepted and is reflected in the UK's national healthcare policies ${ }^{[1]}$. Recent guidance from the National Institute for Clinical Excellence (NICE) on developing transition services for young people identifies nine overarching principles ${ }^{[2]}$, the first of which emphasises the necessity of involving young people in the design and delivery of the transition service.

Ideally, transition should be an individualised ageand development-appropriate process, through which each young person is empowered to self-manage, with support from their families and multidisciplinary team (MDT). It is widely recognised that young people who are not engaged in self-management may become non-adherent to therapy. For those with haemophilia, this can have a lifelong impact on joint health and quality of life ${ }^{[3,4]}$.

While transition is routinely discussed in haemophilia review clinics, anecdotal reports from individuals with haemophilia in the UK suggest that the transition process is often poorly planned, leaving them feeling lost and unsupported by the healthcare professionals who, until this point, have been core members of their support network. The views of young people and their families need to be more often sought in relation to the process or outcome of their transition process.

Haemnet initiated the three-year 'Transforming Transition' programme to support nurses to improve transition for young people with haemophilia ${ }^{[3]}$. The aim of the project was to secure changes in working practices that enabled nurses to drive improved transition outcomes, and enhanced self-management by people with haemophilia. The programme included an exercise designed to capture the recent transition experiences of young people with haemophilia or other bleeding disorders.

\section{METHODOLOGY}

Three young people with inherited bleeding disorders were recruited to undertake a telephone survey of young people who had recently transferred to adult services. All three were volunteers at The Haemophilia Society (the UK patient support group) and had themselves recently transitioned to adult services. They received training in qualitative interviewing techniques before undertaking the interviews.

An interview guide was developed by the Haemnet project team. This was designed to capture details of the service that people had experienced, specifically:

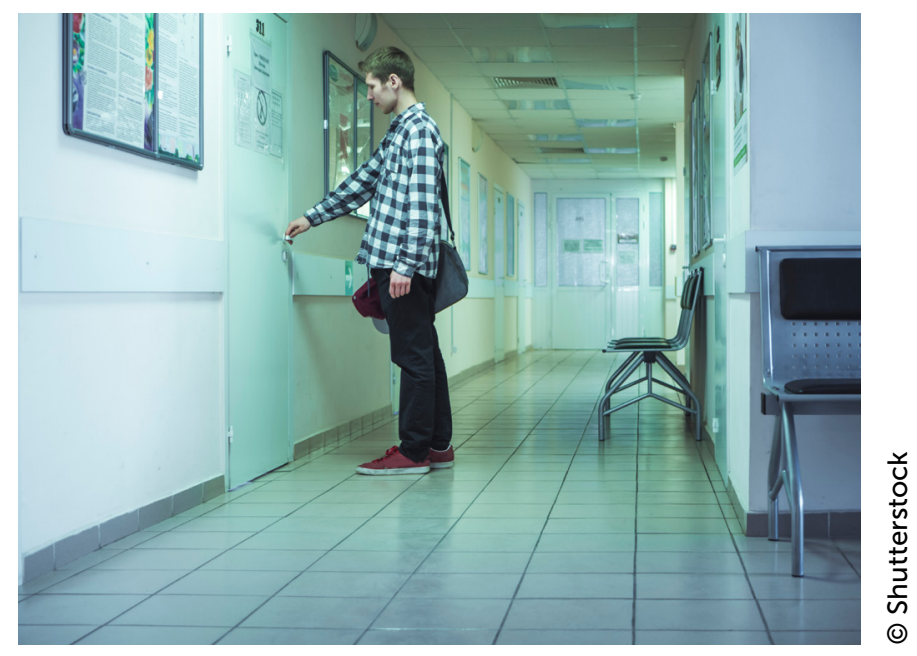

Poor planning can leave young people transitioning from paediatric to adult care feeling lost and unsupported. Those interviewed for the Transforming Transition project identified communication as being key to feeling informed and prepared for changes in their care

- Age at transfer to adult services

- Whether or not transition was planned

- Age (and motivation) for taking on self-management

- Communication with clinical teams

- Whether or not the interviewee felt adequately supported

- Current adherence with treatment

- Confidence in self-management

- What could have been done better.

However, interviewees were encouraged to tell their stories in their own words.

Interviewees were identified by staff of The Haemophilia Society, which benefited from a donation for each completed interview.

All interviews were conducted by telephone and were digitally recorded; each lasted about 30-45 minutes. In addition, the interviewers were encouraged to take field notes during interviews. Digital sound files were professionally transcribed, and transcripts were analysed by the project team to identify key themes around transition experiences, self-management and living with haemophilia.

\section{RESULTS}

The interviewees were 13 young people with bleeding disorders, aged 18-21 years (Table 1), and six parents of seven young people aged 14-24 years (Table 2). Interviewees attended geographically diverse haemophilia centres (Basingstoke, Belfast, Birmingham, Cambridge, Cardiff, Leeds, Lincoln, Liverpool, London (Royal Free, St Thomas's), Manchester, Nottingham, and Oxford). 


\section{Patient experiences}

The ages at which interviewees with bleeding disorders transferred to adult care ranged from 15 to 18 years (Table 1). Interviewees' descriptions of transition were broadly similar whether they had mild or severe haemophilia. Only half of interviewees described a transition process that could be said to have been fairly well planned:

"It was discussed probably sort of around 14. My paediatric clinician was saying how it was going to work with the transition at the time. And just saying that I'd be staying in the same area but going to different doctors. It seemed quite natural. Through the last years of paediatric sort of time, there was a bit more of an emphasis on what I was doing. And looking back at it, you can tell they were sort of trying to build me up to actually taking more responsibility on." [P1]

In some interviews, there was evidence to suggest that earlier exposure to the adult team during paediatric clinic visits was beneficial to the transition process:

"I was about 16/17 when they first mentioned about having to move. You go over to the [hospital] with them [paediatric team] and other people who are about your age looking to transfer over ... you talk to the nurses and doctors. It was good because when you did move over you already knew them and they knew who you were. So it was like ... it was better, it made it easier." [P5]

For these patients, the overall experience of transition was positive and 'undramatic'.

"It was kind of, you know... It wasn't a major thing. You went from one bit of the hospital to another and the people were largely the same." [P8]

However, one boy who was experiencing transition at the time of his interview said he was not aware of it, while others suggested there was no preparation:

"I haven't really heard much about it, so I'm not quite sure. But I guess I'm fine with it. I just need to know kind of what to do and stuff" [P4]

"It was just like, 'Well, this is happening. Next time you come in you won't be seeing me, you'll be seeing this doctor.' It's kind of impersonal, but at the same time it wasn't traumatic or anything" [P2]
"I don't really think there was a conversation ... it just happened" [P3]

For two patients, there appeared to be no prior discussion of transition or preparation for moving to a new centre:

"It was just ... I was getting too old to be at the children's section and soon I'd have to move up." [P9]

"It was 'Next time you come in you'll be in adult services and you'll be seeing $\operatorname{Dr} X$,' and that was it." [P11]

Indeed, good communication appears to be key to successful transition, and is strongly supported by the responses received from the young people during the interview process. Those who described a positive experience spoke about good communication between the paediatric and adult teams, as well as strong communication with themselves.

"It was kind of easy really ... because of all the preparation they did ... everyone there is really nice and they make it easier for you to move." [P5]

"Yes, it was really good, like, having the consistency of the same nurse going through helps." [P6]

"Undramatic. It wasn't a major thing. You went from one bit of the hospital to another and the people were largely the same." [P8]

Unfortunately, many patients described experiences in which their new adult doctor(s) did not appear to be very well informed about them. While the patients' feelings about this lack of knowledge from doctors varied, most agreed that this made the transition process feel more impersonal and difficult to adjust to.

"I remember the doctors just didn't know me as well as the old ones. Problems only really started when I was seeing doctors who were just seeing me in meetings and just reading out a file as if they didn't really know about my past history ... it just seemed like I was talking to doctors who didn't know me as a patient." [P2]

Among those participants with severe haemophilia, all began to self-infuse factor replacement therapy well before age 11, and long before the age at which they 
her hospital had no haemophilia service so she had received no education around her condition:

"They didn't really tell me if there was anything that I needed to do, say, if I did have another big nosebleed or, like, any sort of bleed. And they mentioned at one point ... giving me some sort of card to carry in my purse with all their details on if ever there was an emergency, but they didn't give me one in the end." [P10]

Our interviews revealed an example of a significant problem with transition. P13, a 19-year-old student with vWD, had been seen at a paediatric clinic near to her home until the age of 17 , after which she had been seen by a new adult doctor when she had bleeding problems. However, she had also recently relocated to attend university, and until the interview was unaware that she could attend a haemophilia centre in her new town instead of travelling home.

\section{Parent experiences}

Interviews with parents of young people who had moved from paediatric services to adult services suggested that transition can be a difficult time for parents too (Table 2).

"One minute you're at paeds, you know, you have your appointments, then it's like, 'Oh, next time you're over at the adult thing.' You know, if we could have stuck with the paediatric bit forever we would do. But that's purely because of the staff." [Pa2]

Some felt excluded from the process, although they largely accepted the need for a move:

\section{"I found it a little bit upsetting that I couldn't go and sit in reviews anymore ... it was almost like letting go of him ... that was a little bit traumatic." [Pa1]}

"Whether or not 18 is the right age, I don't know because there's very different levels of being 18." [Pa2]

Not all parents felt excluded:

"The only thing that changed was the consultant, who I had met a number of times before anyway ... yes (I felt supported). Well, I knew all the people there already." [Pa5]
Ultimately, however, parents accepted and welcomed this exclusion as a necessary part of their child's development, even though it meant watching as they made mistakes:

"Once he realised that he was going to be given more control and more decisionmaking, he was adamant... he absolutely wanted to go in on his own. I suppose it was a case of up until that point he felt his life was 'managed' - in inverted commas - in a huge way and he wanted some control back - which is absolutely understandable. It was a learning curve for him and he got some things wrong and then he corrected them, and then he got some things right. But to be honest with you, I've always trusted his judgement in terms of his bleeds, because he's always been very good at realising what's going on very quickly." [Pa1]

When asked what could have made the transition process easier, one parent felt that the hospital staff had simply followed established procedures and had overruled their opinions, which had led to conflict. Another stressed that there should have been more preparation:

"Easing into the situation rather than, like I say, 'Here you go, there you go.' I think there should be a little bit more transition for that transitional period. You know, when you go from junior school to high school you always have a day or two at the new high school, so it needs to adopt something similar." [Pa2]

Another urged centre staff to facilitate introductions to alternative centres, rather than 'holding on' to patients:

"You know, if they know they're going to university, perhaps say, 'Yes, there's a centre there you can go to if you need. '" [Pa6]

\section{DISCUSSION}

The interviews revealed that transition tended to take place around the age of 16 , although factors such as relocation for university could delay this process. The extent of planning and support for individuals leading up to and during the transfer to adult services varied across the cohort interviewed, with half describing the process as fairly well planned. 


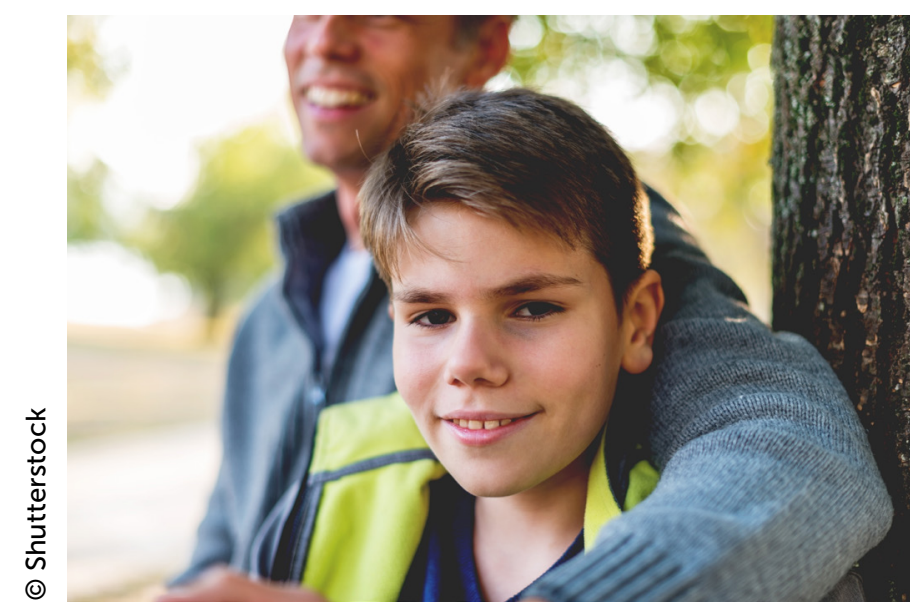

With the right planning, transition can be a positive experience. A personalised approach, early exposure to the adult care team, good communication, and supporting parents and carers are important factors

For those reporting a positive experience, early exposure to the adult team was described as beneficial to the experience of transfer and was underpinned by good communication, both with themselves and between the paediatric and adult teams. For many, but not all, the transfer to adult services brought with it the need to develop new and different relationships with the clinical team. This is a process that takes time and can be enhanced by the new team being well informed about the person. Some of the interviewees reported an apparent lack of knowledge about them, which was described as making the process feel more impersonal and adding to difficulties in adjusting to the adult service.

Transition takes place at a time of many changes for young people, such as leaving school, taking exams, going to university, leaving home, starting a career and new relationships - all of which need to be factored in when supporting young people with bleeding disorders to successfully transfer to adult services. The young people interviewed all emphasised a need for communication throughout the process, so that they feel informed and prepared for the changes that may happen regarding their care. The best outcomes reported came from those who had experienced clear and effective communication with their clinical team and had prior contact and exposure to members of the adult care team.

Transition to adult services was also a time of change for the parents interviewed, with some welcoming the move to greater independence and others less comfortable with what was happening. Again, a feeling of exclusion was reported by some, reinforcing the need to engage families and carers in preparing for transition.
The interviews emphasise that transition needs to remain true to its definition as a process of changing from one state or condition to another in the context of haemophilia and bleeding disorder care. Abrupt and sudden changes can leave patients feeling uninformed and less in control of their care, which can lead to selfmanagement issues in adult life.

From an early age, those with severe haemophilia tended to be well prepared by their paediatric teams to be confident in self-managing their condition. They learned to self-infuse between the ages of $5-11$, and reported feeling confident in tailoring their treatment around their daily routine. Some reported that their transition was not planned, but they did not consider it to have had a negative effect on their transfer to adult care. Interestingly, the interviewees with mild haemophilia reported that their transition was planned, in opposition to the views more commonly expressed in haemophilia care. For the women with vWD who were interviewed, there was rarely a transition process at all. This highlights the importance of ensuring that patients across the spectrum of bleeding disorders are adequately supported during the process of transition.

The interviews highlight the need for a personalised approach to transition, be it young people developing the skills to successfully manage their condition in adult services; services providing support for families and carers to be comfortable with the changes underway; or the provision of planned transition for young people across all bleeding disorders and severities. The interviews also reinforce the need to continue to address the specific needs for women with bleeding disorders as they transfer to adult services, including access to clinicians who are comfortable and confident in discussing women's issues.

The insights gained from this phase of the Transforming Transition programme were submitted to NICE as part of the consultation on its guideline on transition from children's to adult services ${ }^{[2]}$.

\section{ACKNOWLEDGEMENTS}

The Transforming Transition programme was designed by Haemnet and funded by an educational grant from the Burdett Trust for Nursing. Patient interviews were conducted by Luke Pembroke, Laurence Woollard and Rob Barnard, all of whom were, at the time, youth ambassadors for The Haemophilia Society.

This article reports on a survey to which participants responded knowing any comments may be reported. 
Table 1: Characteristics of people with bleeding disorders interviewed

\begin{tabular}{|c|c|c|c|c|c|c|c|c|c|c|}
\hline PARTICIPANT & $\begin{array}{l}\text { AGE } \\
\text { (YEARS) }\end{array}$ & $\begin{array}{l}\text { DIAGNOSIS } \\
\text { OF SUBJECT }\end{array}$ & $\begin{array}{l}\text { AGE AT TRANSFER } \\
\text { TO ADULT } \\
\text { SERVICE (YEARS) }\end{array}$ & $\begin{array}{l}\text { WAS } \\
\text { TRANSITION } \\
\text { "PLANNED"? }\end{array}$ & $\begin{array}{l}\text { WAS } \\
\text { TRANSITION } \\
\text { "SUPPORTED"? }\end{array}$ & TREATMENT & $\begin{array}{l}\text { AGE AT START } \\
\text { OF SELF- } \\
\text { INFUSING }\end{array}$ & MOTIVATION & $\begin{array}{l}\text { CONFIDENCE } \\
\text { IN SELF- } \\
\text { MANAGEMENT }\end{array}$ & $\begin{array}{l}\text { ADHERENCE } \\
\text { (SELF-REPORTED) }\end{array}$ \\
\hline P1 & 20 & Severe A & 15 & Yes & Yes & Prophylaxis & 5 & $\begin{array}{l}\text { "I didn't really like } \\
\text { having other people } \\
\text { doing my treatment" }\end{array}$ & Yes & $\begin{array}{l}\text { Good (but relies on } \\
\text { regularity of dosing } \\
\text { every other day) }\end{array}$ \\
\hline P2 & 21 & Severe B & 18 & No & No & Prophylaxis & 6 & $\begin{array}{l}\text { School trip; seen alone } \\
\text { at clinic since age } 16\end{array}$ & Yes & Mostly good \\
\hline P3 & 18 & Severe A & $16 / 17$ & No & No & Prophylaxis & 9 & School trip & Yes & Mostly good \\
\hline P4 & 17 & Severe A & 17 & No & No & Prophylaxis & 11 & & Yes & Good \\
\hline P5 & 19 & Mild A & 18 & Yes & Yes & On demand & - & - & Poor & N/A \\
\hline P6 & 21 & Mild A & $17 / 18$ & Yes & Yes & On demand & - & $\begin{array}{l}\text { Seen alone at clinic } \\
\text { since age } 16\end{array}$ & Yes & N/A \\
\hline P7 & 21 & Mild A & 16 & Yes & Yes & On demand & - & - & On demand & N/A \\
\hline P8 & 19 & Severe A & 16 & Yes & Yes & Prophylaxis & 8 (port) & $\begin{array}{l}\text { Seen alone at clinic } \\
\text { since age } 14\end{array}$ & Yes & Good \\
\hline P9 & 21 & Mild vWD & 15 & No & No & TXA & - & - & Yes & On demand \\
\hline P10 & 21 & vWD & 18 & No & No & OCP and TXA & $\begin{array}{l}\text { Infused by } \\
\text { clinic nurse }\end{array}$ & - & Poor & Relies on mother \\
\hline P11 & 20 & Severe vWD & 18 & Yes & Yes & TXA & $\begin{array}{l}9 \text {, taught by } \\
\text { her nurse }\end{array}$ & Encouraged by nurse & Good & On demand \\
\hline P12 & 20 & $\begin{array}{l}\text { Severe vWD } \\
2 \mathrm{~A}\end{array}$ & 14 & No & No & $\begin{array}{l}\text { TXA on } \\
\text { demand }\end{array}$ & $\begin{array}{l}\text { Infused by } \\
\text { clinic nurse }\end{array}$ & - & Poor & Relies on mother \\
\hline P13 & 19 & Mild vWD & 17 & No & No & OCP and TXA & N/A & - & Reasonable & $\mathrm{N} / \mathrm{A}$ \\
\hline
\end{tabular}

vWD: von Willebrand's disease

TXA: tranexamic acid

OCP: oral contraceptive pill

Table 2: Transition experiences of parents of young people with bleeding disorders

\begin{tabular}{|c|c|c|c|c|c|c|c|c|c|}
\hline PARTICIPANT & $\begin{array}{l}\text { AGE OF CHILD } \\
\text { (YEARS) }\end{array}$ & $\begin{array}{l}\text { CHILD'S } \\
\text { DIAGNOSIS }\end{array}$ & $\begin{array}{l}\text { AGE AT TRANSFER } \\
\text { TO ADULT SERVICE } \\
\text { (YEARS) }\end{array}$ & $\begin{array}{l}\text { WAS } \\
\text { TRANSITION } \\
\text { "PLANNED"? }\end{array}$ & $\begin{array}{l}\text { WAS } \\
\text { TRANSITION } \\
\text { "SUPPORTED"? }\end{array}$ & $\begin{array}{l}\text { AGE AT START OF } \\
\text { SELF-INFUSING } \\
\text { (YEARS) }\end{array}$ & MOTIVATION & $\begin{array}{l}\text { CONFIDENCE } \\
\text { IN SELF- } \\
\text { MANAGEMENT }\end{array}$ & $\begin{array}{l}\text { ADHERENCE } \\
\text { (SELF-REPORTED) }\end{array}$ \\
\hline Pa1 & 24 & Severe B & 16 & Yes & Yes & $<10$ & N/A & Yes & Good \\
\hline $\mathrm{Pa} 2$ & 19 & Severe A & 18 & No & No & $16 / 17$ & - & Moderate & Poor - reliance on parents \\
\hline $\mathrm{Pa} 3$ & $14 / 17$ & Severe A & 16 & No & No & & & & \\
\hline $\mathrm{Pa} 4$ & 21 & Mild A & 16 & Yes & No & N/A & & Poor & Doctor-dependent \\
\hline $\mathrm{Pa} 5$ & 19 & Severe A & 16 & Yes & Yes & 8 & & & \\
\hline $\mathrm{Pa} 6$ & 19 & Mild vWD & 17 & No & No & N/A & - & None & Poor - reliance on parents \\
\hline
\end{tabular}




\section{REFERENCES}

1. Chaplin S. Transition from paediatric to adult services in haemophilia. J Haem Pract 2016;3(1). doi:10.17225/jhp00059.

2. National Institute for Health and Care Excellence. Transition from children's to adults' services for young people using health or social care services. NICE guideline NG43. February 2016. Available at https://www.nice.org.uk/guidance/ng43 (accessed 1 October 2018).
3. Dodgson S, Holland M, Pembroke L, Khair K. Transforming Transition: enhancing practice in haemophilia. J Haem Pract 2018; 5(1). doi: 10.17225/jhp00120.

4. Young G. From boy to man: recommendations for the transition process in haemophilia. Haemophilia 2012; 18(s5): 27-32. doi: 10.1111/j.1365-2516.2012.02893.x.

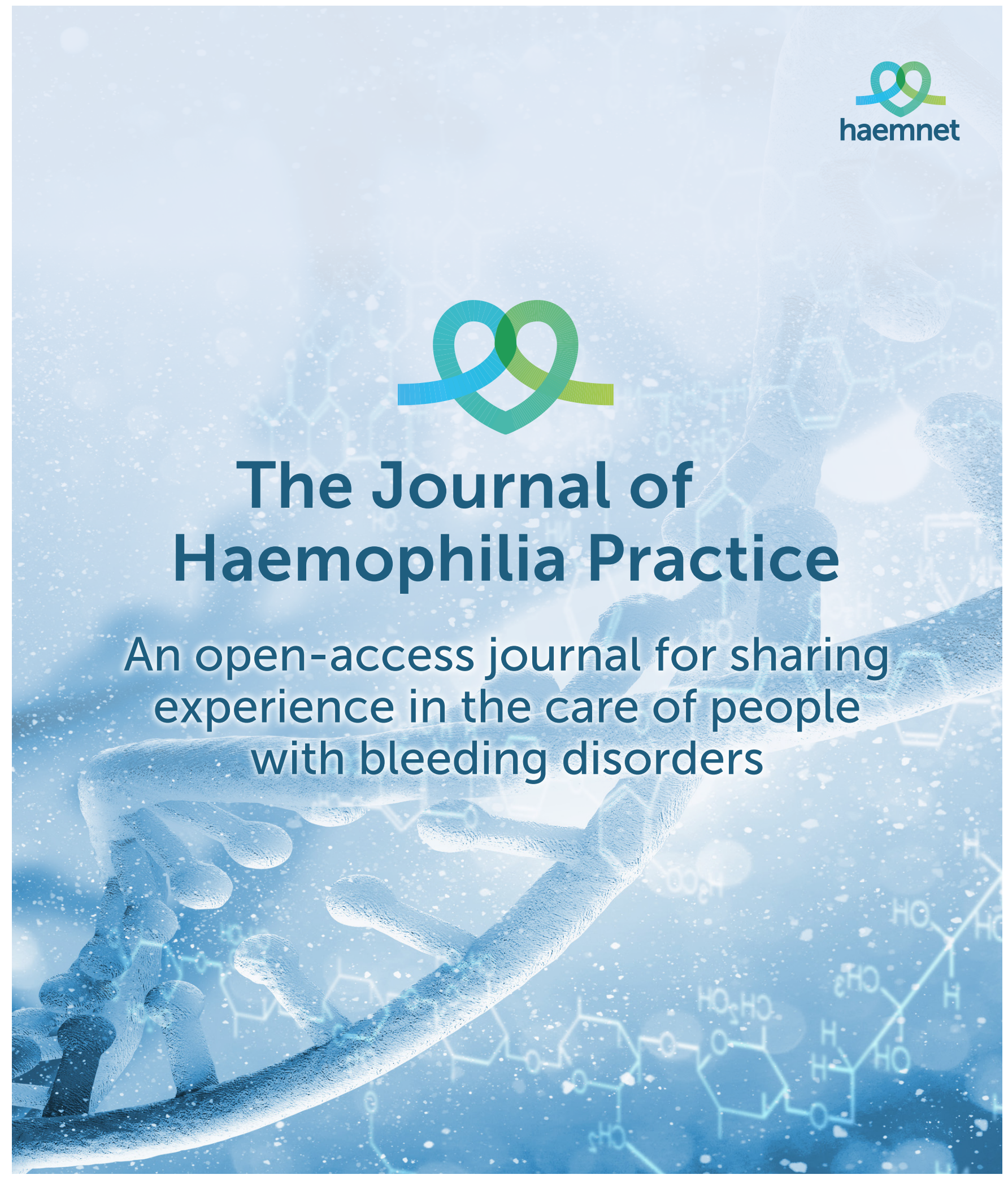

